Please refer to the following:

Jármai K, Farkas J

Comparison of rectangular and square box columns composed from cellular plates with welded and rolled stiffeners

ENGINEERING STRUCTURES 60:(Febr) pp. 199-205. (2014)

\title{
Comparison of rectangular and square box columns composed from cellular plates with welded and rolled stiffeners
}

\author{
Károly Jármai ${ }^{1}$, Józs ef Farkas ${ }^{2}$ \\ ${ }^{1,2}$ University of Miskolc, Hungary, ${ }^{1}$ Professor, altjar@uni-miskolc.hu, ${ }^{2}$ Emeritus professor, altfar@uni-miskolc.hu
}

\section{Abstract}

A cantilever column is loaded by a compression force and a bending moment caused by a horizontal force. It can be derived that, in the case of uniaxial bending, the rectangular cross section is more econo mic than the square one. In the given numerical case, the plate thicknesses are too large for enabling fabrication. There fore stiffened plates should be used. Thus, the aim of the present study is to elaborate the minimum cost design of a column with rectangular cross-section and cellular plate walls. Cellu lar plates are constructed from two plates and longitudinal stiffeners welded between them. Previous studies have shown that welded T-stiffeners are more economic than the halved rolled I-section stiffeners, thus, welded T-stiffeners are used.

Stress and horizontal deformation constraints are formu lated. In the stress constrain t, face plate buckling is taken into account by using effective widths. Local buckling constraint is used for the web of T-stiffeners.

Variables are as follows: heights of welded T-sections, thicknesses of stiffener webs and flanges, number of stiffeners in both directions, main dimensions of the rectangular box section, thicknesses of outer and inner face plates in smaller and larger walls.

The cost function is formu lated according to the fabrication sequence and consis ts of cost of material, welding and painting. The constrained function minimization is performed by using an effective mathematical optimization method.

2. Keywords: structural optimization, minimum cost design, cellular plates, columns.

\section{Introduction}

Steel columns are widely used for buildings, bridges, as supports of highways etc. The optimum design of such columns has been treated, which constructed from various structural types, such as circular cylindrical unstiffened and stiffened shells and square box sections with walls from stiffened and cellular plates [1]. Bending caused by horizontal force plays an important role in seismic design. A detailed literature survey concerning the cellu lar plates can be found in [1].

Steinhardt [2] has proposed a design method for box beams with stiffened flange plates using formulae for effective plate width. Nakai et al. [3] have worked out empirical formu lae for stiffened box stub-columns subject to combined actions of compression and bending.

Ge et al. [4] and Usami et al. [5] have studied the cyclic behaviour and ductility of stiffened steelbox colu mns used as bridge piers. Longitudinal flat plate stiffeners and diaphrag ms as well as constant compressive axial force and cyclic lateral loading have been considered. Empirical formulae have been proposed for ultimate strength and ductility capacity.

Other papers about bridge piers can be found in conference proceedings as follows: Yamao,T. et al. [6], Ohga,M. et al. [7] and Hirota,T. et al. [8]

In our previous studies it has been shown that, in the case of uniaxial compression, cellular plates are more economic than a longitudinally stiffened ones (Farkas \& Jármai [9]). In a study we have elaborated a minimum cost design of a cellular plate subject to uniaxial compression (Farkas \& Jármai [10]). This method is used in the present paper for a square box column constructed from four equal cellular plates.

A column is loaded by a compression force $N_{F}$ and a bending moment caused by a horizontal force $H_{F}=0.1 N_{F}$ shown in Figure 1. Firstly, the unstiffened rectangular cross section is optimized. It will be derived that, in the case of uniaxial bending, the rectangular cross section is more economic than the square one.

It will be shown that, in the given numerical case, the plate thicknesses are too large for fabrication. Therefore stiffened plates should be used.

Results obtained for square box columns have shown that the cellular plate elements are more economic than the 
plates stiffened on one side [1].

The stiffeners can be made of halved rolled I-sections (UB profiles are used) or by welded T-sections. Advantages of welded T-sections are that their dimensions (mainly the web thickness) can be freely varied. The economy of welded T-stiffeners depends on local buckling strength caused by the stress state (compression or bending).

Thus, the aim of the present study is to elaborate the minimu m cost design of a colu mn with rectangular and square cross-sections and cellular plate walls. We have considered the welded structure with initial imperfections according to the standards $[11,12]$. Dented structures have not been considered [13]. That is another problem.

\section{Numerical data}

The factored compression force is $N_{F}=10^{8}[\mathrm{~N}]$, the height of the column is $a_{0}=15 \mathrm{~m}$, the steel yield stress is $f_{y}=$ $355 \mathrm{MPa}$, the Young-modulus is $E=2.1 \times 10^{5} \mathrm{MPa}$.

\section{Minimum cross-sectional area design of a rectangular unstiffened box section}

The cross-sectional area is expressed as

$$
A=h t_{w}+2 b t_{f}
$$

$h$ is the height of the web, $b$ is the width of the flange, $t_{\mathrm{w}}$ and $t_{\mathrm{f}}$ the thicknesses of the box section.

Local buckling of plate ele ments can be avoid by using the constraints on plate slendernesses, where $\beta$ and $\delta$ are the limit slenderness values for the web and the flange.

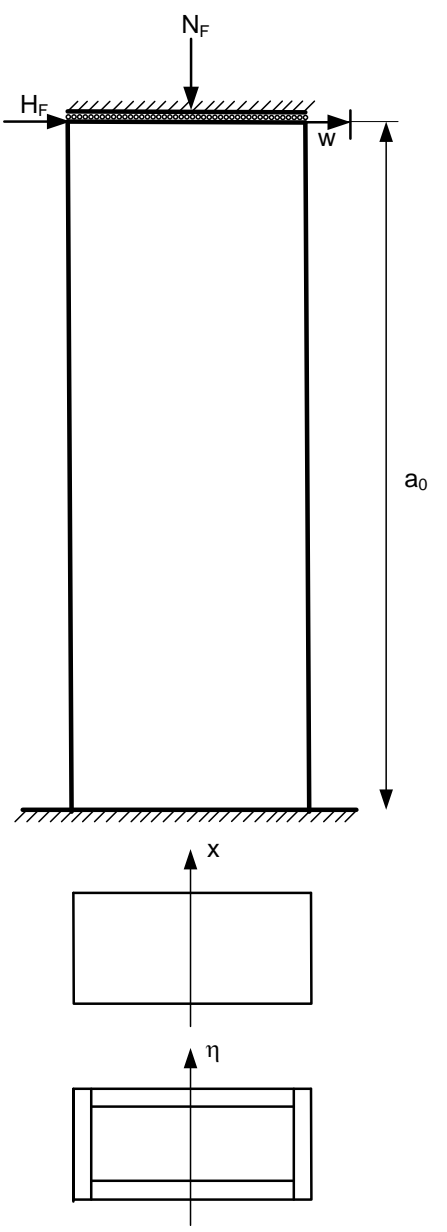

Figure 1: Box column with walls of unstiffened and cellular plates, the two ends are built-in

$$
\frac{h}{t_{w} / 2} \leq \beta, \quad \frac{b}{t_{f}} \leq \delta
$$

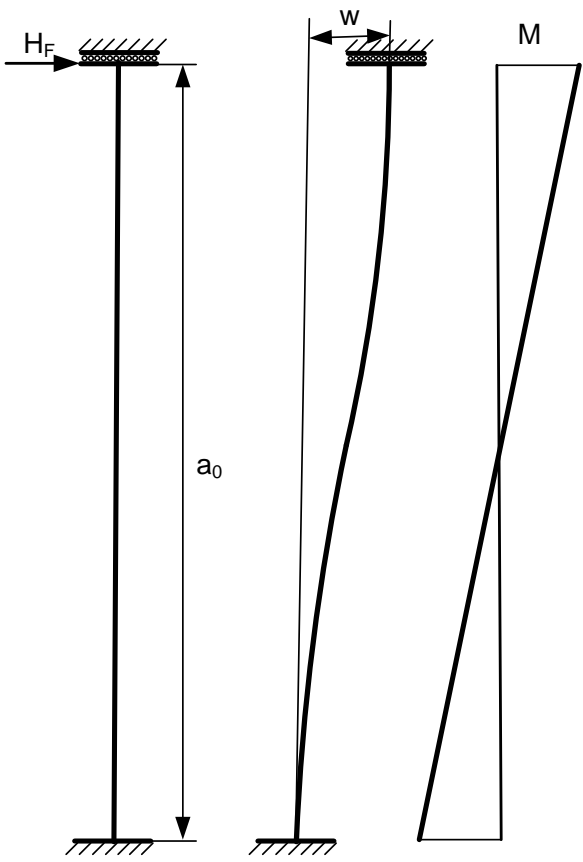

Figure 2: Deformation and bending moment distribution of the column caused by the horizontal force 
According to Eurocode 3 [12]

$$
1 / \delta=42 \varepsilon, \varepsilon=\sqrt{235 / f_{y}}, 1 / \delta=34
$$

The value of $\beta$ depends on the stress distribution (Fig. 2). The stress constraint is formulated as

$$
\sigma=\frac{N_{F}}{A}+\frac{H_{F} a_{0}}{2 W_{x}}=\sigma_{1}+\sigma_{2} \leq f_{y}
$$

Taking the constraints on limiting plate slenderness as active from Eq. 2, since the largest slendernesses give the smallest objective function of the column, the moment of inertia is as follows:

$$
I_{x}=\frac{h^{3} t_{w}}{12}+2 b t_{f}\left(\frac{h}{2}\right)^{2}=\frac{\beta h^{4}}{6}+\frac{\delta b^{2} h}{2}
$$

The section modulus is the following:

$$
W_{x}=\frac{I_{x}}{h / 2}=\frac{\beta h^{3}}{3}+\delta b^{2} h
$$

For

$$
\begin{gathered}
\psi=\frac{\sigma_{1}-\sigma_{2}}{\sigma_{1}+\sigma_{2}} \geq-1 \\
\frac{1}{\beta}=\frac{42 \varepsilon}{0.67+0.33 \psi}
\end{gathered}
$$

Eqs (7) and (8) give the limiting plate slenderness $\beta$ in the case of different edge stresses according to Eurocode 3 [12] Table 5.2. $\sigma \sigma_{2}$ are defined in $\mathrm{Eq}(4)$.

The constraint on horizontal displace ment of the top (Fig. 1) is formu lated for a column which is built-in at both ends (Fig. 2), thus

$$
w=\frac{H_{F} a_{0}^{3}}{12 E \gamma_{M} I_{x}} \leq \frac{a_{0}}{\phi}=15 \mathrm{~mm}
$$

$\gamma_{M}=1.5$ is the safety factor used for factored forces in the case of displacement calculation.

$\phi=1000$.

The optimum is found by using a MathCAD program. It makes a systematic search to find the minimum of the cross-sectional area $(A)$. Table 1 shows the search results. The minimal area means the minimum mass of the column. Note that the actual value of $\beta$ is determined by iteration.

Table 1: Cross-sectional area $(A)$ in the function of dimensions of the rectangular box section. Dimensions in $\mathrm{mm}$, stresses in $\mathrm{MPa}$, cross-sectional area in $\mathrm{mm}^{2}$. The optimum values are marked by bold letters.

\begin{tabular}{cccccccc}
\hline$h$ & $b$ & $w$ & $\sigma_{1}$ & $\sigma_{2}$ & $\sigma$ & $1 / \beta$ & $A \times 10^{-5}$ \\
\hline 2500 & 2250 & 14.9 & 180 & 157 & 337 & 49.00 & 5.529 \\
\hline 2600 & 2110 & 14.8 & 186 & 163 & 349 & 49.15 & 5.370 \\
\hline $\mathbf{2 7 0 0}$ & $\mathbf{2 0 0 0}$ & $\mathbf{1 4 . 7}$ & $\mathbf{1 8 8}$ & $\mathbf{1 6 6}$ & $\mathbf{3 5 4}$ & $\mathbf{4 9 . 3 0}$ & $\mathbf{5 . 3 1 0}$ \\
\hline 2800 & 1910 & 14.2 & 188 & 167 & 355 & 49.33 & 5.325 \\
\hline 2900 & 1820 & 13.8 & 187 & 168 & 355 & 49.44 & 5.351 \\
\hline 3000 & 1730 & 13.4 & 185 & 168 & 353 & 49.56 & 5.392 \\
\hline
\end{tabular}

It can be seen that the displacement constraint is active for smaller $h$-values and the stress constraint is active for 
larger $h$-values.

The optimum plate thicknesses are

$t_{w} / 2=2700 / 49.30=54.8, t_{f}=2000 / 34=58.8 \mathrm{~mm}$.

For the optimum the $\delta$ value is calculated by Eq (3). For the square box a similar systematic search is performed considering that $h=b$.

The optimum dimensions of the unstiffened square box section one can find in a similar way

$h=b=2400 \mathrm{~mm}, \quad \sigma_{1}=174, \sigma_{2}=150,1 / \beta=49, t_{w} / 2=49, t_{f}=70.6 \mathrm{~mm}, A=5.739 \times 10^{-5} \mathrm{~mm}^{2}$.

From the above calculation one can conclude that

(a) The rectangular cross-section is more economic than the square one since

$\frac{A_{s}-A_{r}}{A_{s}} 100=7.5 \%$

where $A_{\mathrm{s}}$ and $A_{\mathrm{r}}$ are the square and the rectangular columns cross sections.

(b) The plate thicknesses are very large, unsuitable for fabrication, thus, stiffened plate walls should be used.

(c) The optimum ratio of $b / t$ for a rectangular box section is $2700 / 2000=1.35$.

Based on the above conclusions, in the present study the optimum cost design of a rectangular box column with cellular plate walls is derived.

\section{Minimum cost design of column of rectangular box section with cellular plate walls}

Cellu lar plates are constructed from two plates and longitudinal stiffeners welded between them. Welded and rolled T-sections are selected for stiffeners. Figures 3 and 4 show the dimensions of cellular plate walls. Variables are as follows: height of welded T-sections $h_{1} / 2=h / 2-t_{f}, h_{11} / 2=h_{2} / 2-t_{f 1}$, thickness of stiffener webs $t_{w}$ and $t_{w 1}$, number of stiffeners in both directions $n$ and $n_{1}$, main dimensions of the rectangular box section $b_{0}$ and $b_{01}$, thicknesses of outer and inner face plates in s maller and larger walls $t$ and $t_{1}$. Ranges of variables are as follows: $t$ $=4-40 \mathrm{~mm}, h=300-1000 \mathrm{~mm}, b=30-300 \mathrm{~mm}$. Ranges for number of stiffeners are $n=2-20 \mathrm{~mm}$.

For the rolled stiffener cross sections we chose universal beam UB profiles. The sizes of the section $t_{\mathrm{f}}, t_{\mathrm{w}}, b$ are calculated by the catalogue of ArcelorMittal [14] with curve fitting calculation in the function of the height of the section $h$.

$$
\begin{aligned}
& t_{\mathrm{f}}=a+b a * h+c^{*} h^{2}+d^{*} h^{3}+e^{*} h^{4}+f^{*} h^{5}+g^{*} h^{6}+h a^{*} h^{7}+p^{*} h^{8} \\
& t_{\mathrm{w}}=a+b a * h+c^{*} h^{2}+d^{*} h^{3}+e^{*} h^{4}+f^{*} h^{5}+g^{*} h^{6}+h a^{*} h^{7}+p^{*} h^{8} \\
& b=a+b a * h+c / h+d^{*} h^{2}+e / h^{2}+f^{*} h^{3}+g / h^{3}+h a^{*} h^{4}+p / h^{4}+r^{*} h^{5}+o / h^{5}
\end{aligned}
$$

A T-stiffener has four dimensions. Using Eqs (10), (11) and (12) the number of unknown dimensions is reduced to one $(h)$. Table 2 shows the approximation functions. For a good approximation so many decimal numbers are needed. The curve fitting is made by TableCurve2D program.

Table 2. Curve fitting approximation of the sizes of the rolled I-beam

\begin{tabular}{c|c|l|l} 
& $t_{\mathrm{f}}$ & \multicolumn{1}{c}{$t_{\mathrm{w}}$} & \multicolumn{1}{c}{$b$} \\
\hline$a$ & -26.93815960004096 & 4.598131596507252 & -1108926.658794802 \\
\hline$b a$ & 0.7030053163805572 & -0.1667245080692302 & 2054.96457373585 \\
\hline$c$ & -0.00569333794408951 & 0.002662252638593643 & 394347552.4221416 \\
\hline$d$ & $2.383106250400329 \mathrm{D}-05$ & $-1.662919423768273 \mathrm{D}-05$ & -2.475920494568994 \\
\hline$e$ & $-5.605511588090933 \mathrm{D}-08$ & $5.42570607199179 \mathrm{D}-08$ & -91315532919.66857 \\
\hline$f$ & $7.662794270183799 \mathrm{D}-11$ & $-1.003562930723944 \mathrm{D}-10$ & 0.001858445891156483 \\
\hline$g$ & $-5.902409057606285 \mathrm{D}-14$ & $1.063362616433473 \mathrm{D}-13$ & 13189053888762.85
\end{tabular}




\begin{tabular}{c|l|l|l}
$h a$ & $2.267417890058806 \mathrm{D}-17$ & $-6.028516559742138 \mathrm{D}-17$ & $-7.856977790442618 \mathrm{D}-07$ \\
\hline$p$ & $-2.999371273581411 \mathrm{D}-21$ & $1.419727612597333 \mathrm{D}-20$ & -1073670362507492 \\
\hline$r$ & & & $1.422535840934241 \mathrm{D}-10$ \\
\hline$o$ & & & $3.744384150518803 \mathrm{D} 16$
\end{tabular}

\section{Geometric characteristics for displacement constraint}

Cross-sectional area for both cellular plate walls

$$
\begin{gathered}
A=\frac{h_{1} t_{w}}{2}+b t_{f}+2 s_{y} t, s_{y}=\frac{b_{0}}{n}, h_{1}=h-2 t_{f} \\
A_{1}=\frac{h_{11} t_{w 1}}{2}+b_{1} t_{f 1}+2 s_{z} t_{1}, s_{z}=\frac{b_{01}-h-3 t}{n_{1}}, h_{11}=h_{2}-2 t_{f 1}
\end{gathered}
$$

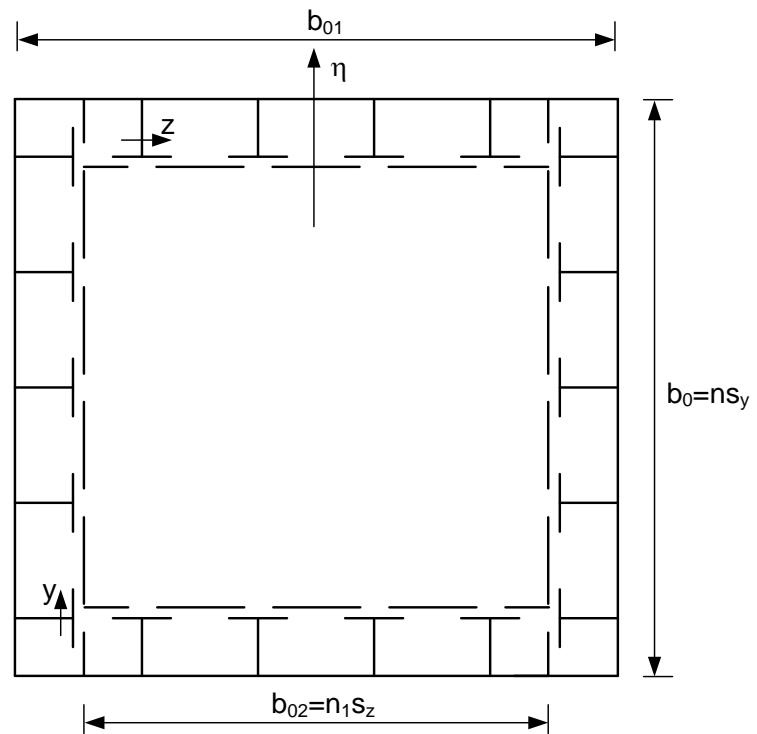

Figure 3: Cross-section of the rectangular box column with cellular plate walls (see a lso Fig. 1). The $\mathrm{T}$-stiffeners and the plate parts are marked by lines only.

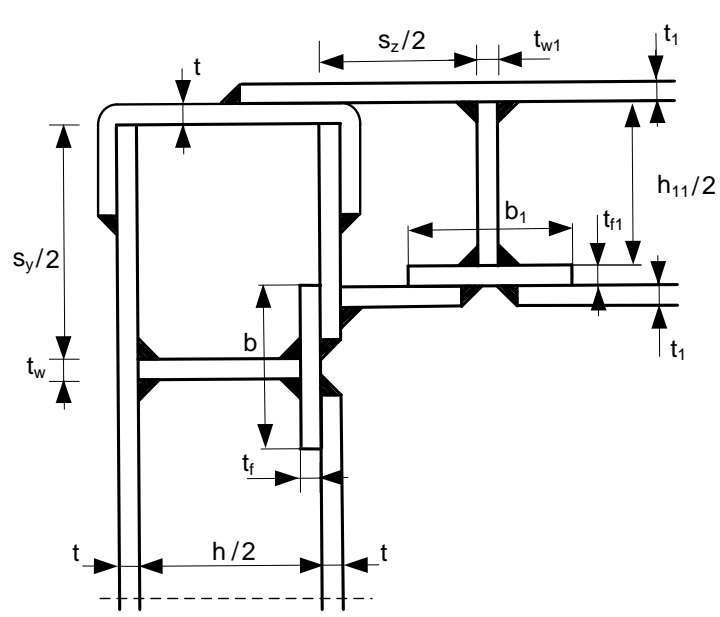

Distance of the gravity centre

$$
z_{G}=\frac{1}{A}\left[\frac{h_{1} t_{w}}{2}\left(\frac{h_{1}+t}{2}\right)+b t_{f} \frac{h_{1}+t+t_{f}}{2}+s_{y} t\left(\frac{h_{1}}{2}+t+t_{f}\right)\right]
$$

Moment of inertia

$$
\begin{aligned}
& I_{y}=s_{y} t z_{G}^{2}+s_{y} t\left(\frac{h_{1}}{2}+t+t_{f}-z_{G}\right)^{2}+\frac{h_{1}^{3} t_{w}}{96}+I_{y 1} \\
& I_{y 1}=\frac{h_{1} t_{w}}{2}\left(\frac{h_{1}+t}{2}-z_{G}\right)^{2}+b t_{f}\left(\frac{h_{1}+t+t_{f}}{2}-z_{G}\right)^{2}
\end{aligned}
$$

Moment of inertia of the whole rectangular box section for axis $\eta$ 


$$
\begin{gathered}
I_{\eta}=2 n I_{y}+2 n A\left(\frac{b_{01}}{2}-z_{G}\right)^{2}+2 \frac{b_{01}^{3} t_{1}}{12}+2 \frac{t_{1}}{12}\left(b_{01}-\frac{h_{1}}{2}-t-t_{f}\right)^{3}+2 I_{\eta 1} \\
I_{\eta 1}=2\left(\frac{h_{11} t_{w 1}}{2}+b_{1} t_{f 1}\right) s_{z}^{2} \frac{n_{1}\left(n_{1}+2\right)\left(n_{1}+1\right)}{24}
\end{gathered}
$$

The displacement constraint is given as

$$
w=\frac{H_{F} a_{0}{ }^{3}}{12 E \gamma_{M} I_{x}} \leq \frac{a_{0}}{\phi}=15 \mathrm{~mm}
$$

or

$$
I_{\eta} \geq I_{0}=\frac{H_{F} L^{2} \phi}{12 E \gamma_{M}}
$$

Numerical data are given in Section 4. With these data the moment of inertia is as follow:

$I_{0}=5.9524 \times 10^{11} \mathrm{~mm}^{4}$.

\section{Geometric characteristics for stress constraint}

The local buckling of face plates is avoided by considering effective plate widths according to Eu rocode 3 [11]: The cross sectional area $A_{e}$ is

$$
\begin{gathered}
A_{e}=\frac{h_{1} t_{w}}{2}+b t_{f}+2 s_{y e} t, s_{y}=\frac{b_{0}}{n}, h_{1}=h-2 t_{f}, s_{y e}=\rho_{y} s_{y} \\
\rho_{y}=\frac{\lambda_{p y}-0.22}{\lambda_{p y}^{2}} \quad \text { if } \quad \lambda_{p y}=\frac{s_{y}}{56.8 \varepsilon t} \geq 0.673, \varepsilon=\sqrt{\frac{235}{f_{y}}} \\
\rho_{y}=1 \quad \text { if } \quad \lambda_{p y}<0.673
\end{gathered}
$$

For the displacement constraint $I_{\eta}$ is used (calculated with $z_{\mathrm{G}}$ for plates with full width), for the stress constraint $I_{\eta \mathrm{e}}$ is used with $z \mathrm{Ge}$ considering the effective plate widths.

$$
\begin{gathered}
z_{G e}=\frac{1}{A_{e}}\left[\frac{h_{1} t_{w}}{2}\left(\frac{h_{1}+t}{2}\right)+b t_{f} \frac{h_{1}+t+t_{f}}{2}+s_{y e} t\left(\frac{h_{1}}{2}+t+t_{f}\right)\right] \\
A_{l e}=\frac{h_{11} t_{w 1}}{2}+b_{1} t_{f 1}+2 s_{z e} t_{1}, s_{z}=\frac{b_{01}-h-3 t}{n}, h_{11}=h_{2}-2 t_{f 1}, s_{z e}=\rho_{z} s_{z} \\
\rho_{z}=\frac{\lambda_{p z}-0.22}{\lambda_{p z}^{2}} \text { if } \quad \lambda_{p z}=\frac{s_{z}}{56.8 \varepsilon t_{1}} \geq 0.673 \\
\rho_{z}=1 \quad \text { if } \quad \lambda_{p z}<0.673 \\
I_{y e}=s_{y e} t z_{G e}^{2}+s_{y e} t\left(\frac{h_{1}}{2}+t+t_{f}-z_{G e}\right)^{2}+\frac{h_{1}^{3} t_{w}}{96}+I_{y 1 e} \\
I_{y l e}=\frac{h_{1} t_{w}}{2}\left(\frac{h_{1}+t}{2}-z_{G e}\right)^{2}+b t_{f}\left(\frac{h_{1}+t+t_{f}}{2}-z_{G e}\right)^{2}
\end{gathered}
$$




$$
\begin{gathered}
I_{\eta e}=2 n I_{y e}+2 n A_{e}\left(\frac{b_{01}}{2}-z_{G e}\right)^{2}+2 \frac{b_{01}^{3} t_{1}}{12}+2 \frac{t_{1}}{12}\left(b_{01}-\frac{h_{1}}{2}-t-t_{f}\right)^{3}+2 I_{\eta 1 e} \\
I_{\eta 1 e}=2\left(\frac{h_{11} t_{w 1}}{2}+b_{1} t_{f 1}\right) s_{z e}^{2} \frac{n_{1}\left(n_{1}+2\right)\left(n_{1}+1\right)}{24}
\end{gathered}
$$

The stress constraint is given by

$$
\sigma=\frac{N_{F}}{A_{0}}+\frac{H_{F} a_{0}}{2 W_{0}} \leq f_{y}
$$

where

$$
A_{0}=2 n A_{e}+2 n_{1} A_{1 e}+4 A_{U}
$$

U-profiles are used to strengthen the corners (Fig. 4) with a cross-sectional area

$$
A_{U}=\left(\frac{h_{1}}{2}+t_{f}+2 t+80\right) t
$$

and

$$
W_{0}=\frac{I_{\eta e}}{\frac{b_{01}}{2}-z_{G e}}
$$

It should be noted that the effect of the g lobal buckling of box colu mn walls can be neglected, since the cellu lar plates have very large torsional stiffness. Calculations show that all the optimized column structures satisfy the constraint on flexural buckling about the weak axis.

\section{Constraint on local buckling of welded stiffener webs}

The webs are subject to uniform compression. According to Eurocode 3 [12]

$$
\frac{h_{1}}{2 t_{w}} \leq 42 \varepsilon_{1}, \varepsilon_{1}=\sqrt{\frac{235}{\sigma}}
$$

and

$$
\frac{h_{11}}{2 t_{w 1}} \leq 42 \varepsilon_{1}
$$

\section{Fabrication constraints}

In order to guarantee the welding of stiffeners web to the base plates, to have enough space, the following constraints should be considered

$$
n \leq \frac{b_{0}}{300+b}, n_{1} \leq \frac{b_{01}}{300+b_{1}}
$$

$300 \mathrm{~mm}$ space is needed to ease the welding process

\section{Cost function}

The cost function is formulated according to the fabrication sequence.

(1) Welding of outer face plates with butt welds (SAW - submerged arc welding). A plate element has sizes of $6000 \times 1500 \mathrm{~mm}$ or less.

Plate of sizes $a_{0} \times b_{0}$ : volume $V_{0}=a_{0} b_{0} t$, weld length $L_{W 0}=2 b_{0}+(q-1) a_{0}$,

$$
K_{W 0}=k_{W}\left(\Theta \sqrt{3 q \rho V_{0}}+1.3 C_{W} t^{n_{0}} L_{W 0}\right), k_{W}=1.0 \$ / \mathrm{min}
$$


where $k_{\mathrm{W}}$ is the specific welding cost, we used $60 \$ /$ hour which can be valid in Europe. $q$ is the number of plate elements in the direction of $b_{0}$ so that $b_{0} / q \leq 1500 \mathrm{~mm}$,

$\Theta$ is the factor of complexity,

$\rho$ is the density of the steel,

$t$ is the thickness of the plate,

$L_{\mathrm{Wi}}$ is the weld length.

The factor of complexity of the as sembly is taken as $\Theta=2$.

$$
\begin{gathered}
\text { For } t<11 \quad C_{W}=0.1346 \times 10^{-3}, n_{0}=2 \\
\text { for } \quad t \geq 11 \quad C_{W}=0.1033 \times 10^{-3}, n_{0}=1.904
\end{gathered}
$$

Plate of sizes

$$
\begin{gathered}
a_{0} x b_{01}: V_{01}=a_{0} b_{01} t_{1} ; L_{W 01}=2 b_{01}+\left(q_{1}-1\right) a_{0} \\
K_{W 01}=k_{W}\left(\Theta \sqrt{3 q_{1} \rho V_{01}}+1.3 C_{W} t_{1}^{n_{0}} L_{W 01}\right)
\end{gathered}
$$

$q$ and $q_{1}$ are the numbers of plate strips of width smaller than $1500 \mathrm{~mm}$.

(2) Welding of stiffeners' webs to outer face plates and to flange with double fillet welds (GMAW-C gas metal arc welding with $\mathrm{C}_{2}$ ).

Plate of sizes $a_{0} \times b_{0}$.

For welded stiffeners:

$$
V_{1}=\left(\frac{h_{1}}{2} t_{w}+b t_{f}\right) a_{0} n+V_{0}, L_{W 1}=4 a_{0} n
$$

For rolled stiffeners:

$$
V_{1}=\left(\frac{h_{1}}{2} t_{w}+b t_{f}\right) a_{0} n+V_{0}, L_{W 1}=2 a_{0} n
$$

For welded stiffeners:

$$
K_{W 1}=k_{W}\left(\Theta \sqrt{(2 n+1) \rho V_{1}}+1.3 \times 0.3394 \times 10^{-3} a_{W}^{2} L_{W 1}\right)
$$

For rolled stiffeners:

$$
K_{W 1}=k_{W}\left(\Theta \sqrt{(n+1) \rho V_{1}}+1.3 \times 0.3394 \times 10^{-3} a_{W}^{2} L_{W 1}\right)
$$

$a_{W}=0.4 t_{w}$ but $a_{W \min }=4 \mathrm{~mm}$

Plate of sizes $a_{0} \times b_{01}$.

For welded stiffeners:

$$
V_{11}=\left(\frac{h_{11}}{2} t_{w 1}+b_{1} t_{f 1}\right) a_{0} n_{1}+V_{01}, L_{W 11}=4 a_{0} n_{1}
$$

For rolled stiffeners:

$$
V_{11}=\left(\frac{h_{11}}{2} t_{w 1}+b_{1} t_{f 1}\right) a_{0} n_{1}+V_{01}, L_{W 11}=2 a_{0} n_{1}
$$

For welded stiffeners:

$$
K_{W 11}=k_{W}\left(\Theta \sqrt{\left(2 n_{1}+1\right) \rho V_{11}}+1.3 x 0.3394 x 10^{-3} a_{W 1}^{2} L_{W 11}\right)
$$

For rolled stiffeners:

$$
K_{W 11}=k_{W}\left(\Theta \sqrt{\left(n_{1}+1\right) \rho V_{11}}+1.3 \times 0.3394 \times 10^{-3} a_{W 1}^{2} L_{W 11}\right)
$$

$a_{W 1}=0.4 t_{w 1}$ but $a_{W 1 \min }=4 \mathrm{~mm}$

(3) Welding of inner plate strips of width $s_{y}$ and $s_{z}$ from 3-3 parts with butt welds excluding the outside strips: 


$$
\begin{gathered}
V_{2}=a_{0} s_{y} t \\
K_{W 2}=(n-1) k_{W}\left(\Theta \sqrt{3 \rho V_{2}}+1.3 C_{W} t^{n_{\circ}} 2 s_{y}\right) \\
V_{21}=a_{0} s_{z} t_{1} \\
K_{W 21}=\left(n_{1}-1\right) k_{W}\left(\Theta \sqrt{3 \rho V_{21}}+1.3 C_{W} t_{1}^{n_{0}} 2 s_{z}\right)
\end{gathered}
$$

(3a) Welding of the outside strips of width $s_{y} / 2$ and $s_{z} / 2$ :

$$
\begin{gathered}
V_{2 a}=a_{0} s_{y} t / 2, V_{21 a}=a_{0} s_{z} t_{1} / 2 \\
K_{W 2 a}=2 k_{W}\left(\Theta \sqrt{3 \rho V_{2 a}}+1.3 C_{W} t^{n_{0}} s_{y}\right) \\
K_{W 21 a}=2 k_{W}\left(\Theta \sqrt{3 \rho V_{21 a}}+1.3 C_{W} t_{1}{ }^{n_{o}} s_{z}\right)
\end{gathered}
$$

(4) Welding of inner face plate strips to the stiffener flanges with double fillet welds:

$$
\begin{gathered}
V_{3}=V_{1}+a_{0} b_{0} t, L_{W 2}=2 a_{0} n \\
K_{W 3}=k_{W}\left(\Theta \sqrt{(n+2) \rho V_{3}}+1.3 \times 0.3394 \times 10^{-3} a_{W 2}^{2} L_{W 2}\right)
\end{gathered}
$$

$a_{W 2}=0.7 t$ but $a_{W 2 \min }=3 \mathrm{~mm}$

$$
\begin{gathered}
V_{31}=V_{11}+a_{0}\left(b_{01}-h-3 t\right) t_{1}, L_{W 21}=2 a_{0} n_{1} \\
K_{W 31}=k_{W}\left(\Theta \sqrt{\left(n_{1}+2\right) \rho V_{31}}+1.3 \times 0.3394 \times 10^{-3} a_{W 21}^{2} L_{W 21}\right)
\end{gathered}
$$

$a_{W 21}=0.7 t_{1}$ but $a_{W 21 \min }=3 \mathrm{~mm}$

(5) Welding of 2 U-elements to the ends of the smaller wall with 2-2 fillet welds

$$
\begin{gathered}
A_{U}=\left(\frac{h_{1}}{2}+t_{f}+2 t+80\right) t, \quad V_{4}=2 A_{U} a_{0}+V_{3} \\
K_{W 4}=k_{W}\left(\Theta \sqrt{3 \rho V_{4}}+1.3 x 0.3394 x 10^{-3} a_{W 2}^{2} 4 a_{0}\right)
\end{gathered}
$$

(6) Welding of larger walls to the smaller ones with fillet welds

$$
V_{5}=2 V_{4}+2 V_{31}, L_{W 3}=8 a_{0}
$$

$V_{5}$ contains the whole volume (see also Eqs. (44), (48), (55) and (61).

$$
K_{W 5}=k_{W}\left(\Theta \sqrt{4 \rho V_{5}}+1.3 \times 03394 \times 10^{-3} a_{W 21}^{2} L_{W 3}\right)
$$

The material cost

$$
K_{M}=k_{M} \rho V_{5}, k_{M}=1.0 \$ / \mathrm{kg}
$$

The painting cost is calculated as

$$
K_{P}=k_{P} \Theta S_{P}, k_{P}=14.4 \times 10^{-6} \$ / \mathrm{mm}^{2}
$$


Surface to be painted

$$
S_{P}=2 a_{0}\left(2 b_{0}+2 b_{1}-\frac{h_{1}}{2}-t_{f}-2 t-\frac{h_{11}}{2}-t_{f 1}-2 t_{1}\right)
$$

The total cost

$$
\begin{gathered}
K=K_{M}+2\left(K_{W 0}+K_{W 01}+K_{W 1}+K_{W 11}+K_{W 2}+K_{W 2 a}+K_{W 21}+K_{W 21 a}\right)+ \\
+2\left(K_{W 3}+K_{W 31}\right)+K_{W 4}+K_{W 5}+K_{P}
\end{gathered}
$$

\section{Particle swarm optimization}

The particle swarm optimization (PSO) is a parallel evolutionary computation technique developed by Kennedy and Eberhart [15] based on the social behaviour metaphor. A standard te xtbook on PSO, treating both the social and computational paradigms, is Yang [16]. The PSO algorithm is initialized with a population of random candidate solutions, conceptualized as particles. Each particle is assigned a randomized velocity and is iteratively moved through the problem space. It is attracted towards the location of the best fitness achieved so far by the particle itself and by the location of the best fitness achieved so far across the whole population (global version of the algorithm).

Additionally, each member learns from the others, typically from the best performer among them. Every individual of the swarm is considered as a particle in a multidimensional space that has a position and a velocity. These particles fly through hyperspace and remember the best position that they have seen. Members of a swarm communicate good positions to each other and adjust their own position and velocity based on these good positions. The Particle Swarm method of optimization testifies the success of bounded rationality and decentralized decision making in reaching at the global optima. It has been used successfully to optimize extremely difficult multimodal functions.

PSO shares many similarities with evolutionary computation techniques such as Genetic Algorithms $(G A)$. The system is initialized with a population of random solutions and searches for optima by updating generations. However, unlike GA, PSO has no evolution operators such as crossover and mutation. In PSO, the potential solutions, called particles, fly through the problem space by following the current optimum particles.

Each particle keeps track of its coordinates in the problem space which are associated with the best solution (fitness) it has achieved so far. (The fitness value is also stored.) This value is called pbest $\left(\boldsymbol{p}^{b}\right)$. Another "best" value that is tracked by the particle swarm optimizer is the best value, obtained so far by any particle in the neighbours of the particle. This location is called lbest, when a particle takes all the population as its topological neighbours, the best value is a global best and is called gbest $\left(g^{b}\right)$.

The partic le swarm optimizat ion concept cons is ts of, at each time step, changing the velocity of (accele rating) each particle toward its pbest and lbest locations (local version of PSO). Acceleration is weighted by a random term, with separate random numbers being generated for acceleration toward pbest and lbest locations.

In past several years, $P S O$ has been successfully applied in many research and application areas. It is demonstrated that $P S O$ gets better results in a faster, cheaper way compared with other methods.

One reason that $P S O$ is attractive is that there are few parameters to adjust. One version, with slight variations, works well in a wide variety of applications. Particle swarm optimization has been used across a wide range of applications, as well as for specific applications focused on a specific requirement.

The method is derivative free, constrained problems can simply be accommodated using penalty functions. The calculation of the velocity vector and the new position is according to Eqs. 67 and 68.

$$
\begin{gathered}
\boldsymbol{v}_{i}^{k+1}:=\boldsymbol{v}_{i}^{k}+c_{1} r_{1}\left(\boldsymbol{p}_{i}^{b}-\boldsymbol{x}_{i}^{k}\right)+c_{2} r_{2}\left(\boldsymbol{g}^{b}-\boldsymbol{x}_{i}^{k}\right), \\
\boldsymbol{x}_{i}^{k+1}:=\boldsymbol{x}_{i}^{k}+\boldsymbol{v}_{i}^{k+1} t,
\end{gathered}
$$

where $r_{1}$ and $r_{2}$ are independently generated random numbers in the interval $[0,1]$, and $c_{1}, c_{2}$ are parameters with appropriately chosen values. $\boldsymbol{v}$ is the velocity vector, $\boldsymbol{x}$ is the position vector, $t$ is the time step. We have used crazy birds with the probability of $1.5 \%$. The particle nu mber was 500 . The cognitive learning coefficient is $c_{1}=$ 2.0, the social learning coefficient is $c_{2}=1.4$ [17].

In the PSO process the cost function represents the fitness value to be minimized. This value is used for the selection of the alternatives. 
Table 3: Results of optimization with discrete values

\begin{tabular}{ccccc} 
& Rectangular, welded & Square, welded & Rectangular, rolled & Square, rolled \\
\hline$b_{0}$ & 2650 & 4500 & 1110 & 4250 \\
\hline$b_{01}$ & 5250 & 4500 & 4450 & 4250 \\
\hline$q$ & 2 & 3 & 1 & 3 \\
\hline$q_{1}$ & 4 & 3 & 3 & 3 \\
\hline$h$ & 560 & 670 & 610 & 914 \\
\hline$h_{2}$ & 400 & 460 & 914 & 15.9 \\
\hline$t_{w}$ & 8 & 10 & 11.1 & 15.9 \\
\hline$t_{w 1}$ & 6 & 8 & 15.9 & 8 \\
\hline$n$ & 4 & 8 & 4 & 3 \\
\hline$n_{1}$ & 7 & 3 & 6 & 5 \\
\hline$t$ & 6 & 8 & 5 & 5 \\
\hline$t_{1}$ & 7 & 4 & 10 & 23.9 \\
\hline$t_{\mathrm{f}}$ & 40 & 40 & 17.3 & 23.9 \\
\hline$t_{\mathrm{fl}}$ & 30 & 40 & 23.9 & 304.1 \\
\hline$b$ & 300 & 260 & 228.2 & 304.1 \\
\hline$b_{1}$ & 300 & 140 & 304.1 & 96837.6
\end{tabular}

\section{Results of the optimization}

Table 3 shows the optimum sizes of the structure using particle swarm optimization. There are 14 unknowns for welded, 8 unknowns for rolled sections and one constraint on stress (Eq. 32), one on horizontal deformation (Eq. 20), two for stiffener web buckling (Eqs, 36, 37) and two for fabrication (Eq. 38). The stress constraint is usually active. Reliability aspects here in this design has not been considered, but in other cases it has been considered [18].

\section{Conclusions}

A cantilever column loaded by a compression force and a bending moment caused by a horizontal force is investigated. We found that, in case of uniaxial bending, the rectangular cross section is more economic than the square one. In the given numerical example, the plate thicknesses should be too large for fabrication in the unstiffened case. Therefore stiffened plates should be used. We have elaborated the minimum cost design of a column with rectangular cross-section and cellular plate walls.

Stress and horizontal deformation constraints are formulated. In the stress constraint the face plate buckling is taken into account by using effective widths. Local buckling constraint is used for the web of welded T-stiffeners. The calculation shows, that the rectangular cellu lar plate is more economic then the square one. The cost saving is around $13 \%$. Calculations show, that using rolled stiffeners is slightly more econo mic than welded stiffeners due to the fact that less welding is needed.

The cost function is formu lated according to the fabrication sequence and consists of cost of material, welding and painting. The constrained function minimization is performed by using the particle swarm optimization method. The result shows, that using cellular plate for this type of column can be economic, even if the weld ing is an expensive procedure.

\section{Acknowledgements}

The research was supported by the TÁMOP 4.2.4.A/2-11-1-2012-0001 priority project entitled 'National Excellence Program - Development and operation of domestic personnel support system for students and researchers, implemented within the framework of a convergence program, supported by the European Unio n, co-financed by the European Social Fund. The research was supported also by the Hungarian Scientific Research Fund OTKA T 109860 project and was partially carried out in the framework of the Center of Excellence of Innovative Engineering Design and Technologies at the University of Miskolc.

\section{References}


[1] Farkas J, Jármai K. Design and optimization of metal structures. Horwood Publishing, Chichester, UK, 2008. 328 p. (ISBN: 978-1-904275-29-9)

[2] Steinhardt,O. (1975) Berechnungsmodelle für ausgesteifte Kastenträger. In Beiträge zum Beulproblem bei Kastenträgerbrücken. Deutscher Ausschuss für Stahlbau. Berichtsheft 3. 27-35.

[3] Nakai,H., Kitada,T. \& Miki,T. (1985) An experimental study on ultimate strength of thin-walled box stub-columns with stiffeners subjected to compression and bending. Proc. JSCE Structural Eng./Earthquake Eng. 2 No.2. 87-97.

[4] Ge,H., Gao,Sh. \& Usami,Ts. (2000) Stiffened steel box columns. Part 1. Cyclic behaviour. Earthquake Engineering and Structural Dynamics 29 1691-1706.

[5] Usami,Ts., Gao,Sh. \& Ge,H. (2000) Stiffened steel bo x colu mns. Part 2. Ductility evaluation. Earthquake Eng. and Structural Dynamics 29 1707-1722.

[6] Yamao,T.,Matsumara,S.,Hirayae,M.,Iwatsubo,K. (2004): Steel tubular bridge piers stiffened with inner cruciform plates under cyclic loading. In Thin-walled Structures. Proc. $4^{\text {th }}$ Int. Conf. on Thin-walled Structures, Loughborough,UK. 2004. Ed. J. Loughlan. Institute of Physics Publ., Bristol \& Philadelphia, pp. 357-364.

[7] Ohga,M.,Takemu ra,Sh.,Imamura,S. (2004): Nonlinear behaviours of round corner steel box-s ection piers. In Thin-walled Structures. Proc. ${ }^{\text {th }}$ Int. Conf. on Thin-walled Structures, Loughborough,UK. 2004. Ed. J. Loughlan. Institute of Physics Publ., Bristol \& Philadelphia, pp. 365-372.

[8] Hirota,T., Sakimoto,T.,Yamao,T., Watanabe,H. (2004): Experimental study on hysteretic behaviour of inverted L-shaped steel bridge piers filled with concrete. In Thin-walled Structures. Proc. $4^{\text {th }}$ Int. Conf. on Thin-walled Structures, Loughborough,UK. 2004. Ed. J. Loughlan. Institute of Physics Publ., Bristol \& Philadelphia, pp. 373-380.

[9] Farkas J. \& Jármai K. (2006) Optimum design and cost comparis on of a welded plate stiffened on one side and a cellular plate both loaded by uniaxial compression, Welding in the World $\mathbf{5 0}$ No.3-4. 45-51.

[10] Farkas,J. \& Jármai,K. (2007) Economic orthogonally welded stiffening of a uniaxially compressed steel plate. Welding in the World $\mathbf{5 1}$ No.7-8. 74-78.

[11] Eurocode 3 Design of steel structures. Part 1-5: Plated structural elements, 2007.

[12] Eurocode 3 Design of steel structures. Part 1-1: General rules and rules for buildings, 2009.

[13] Xu MC, Soares CG. Assessment of residual ultimate strength for wide dented stiffened panels sub jected to compressive loads. Eng. Struct. 2013; 49: 316-328.

[14] ArcelorMittal Profile Catalogue http://www.arcelormittal.com/sections/fileadmin/redaction/4-Library/ 1-Sales_programme_Brochures/Sales_programme/ArcelorMittal_EN_FR_DE.pdf (accessed July 2013)

[15] Kennedy J, Eberhart RC. Particle swarm optimization. Proc. IEEE Int'l Conf. on Neural Networks, IV, 1942-1948. IEEE service center, Piscataway, NJ, 1995.

[16] Yang XS. Mathematical modeling with multidisciplinary applications. John Wiley \& Sons. 2012, (ISBN 1-118-29441-6)

[17] Farkas J, Jármai K. Optimum design of steel structures. Springer Verlag, Heidelberg, 2013. 288 p. (ISBN 978-3-642-36867-7)

[18] Simoes,L.M.C., Farkas,J., Jármai,K. Reliability-based optimu m design of a square box colu mn constructed from cellu lar plates. In „Design, Fabrication and Economy of Metal Structures, Proc. Int.Conf. Miskolc, 2013. Eds Jármai,K., Farkas,J. Springer Verlag, Heidelberg etc. 2013” pp.69-75. 